\section{The value of small mangrove patches}

Mangroves provide crucial services to humanity, including food, coastal protection, fisheries support, and carbon sequestration (1). However, up to $35 \%$ of mangrove area has been lost since the 1980s, primarily due to coastal development (2). Mangroves are protected under a plethora of international agreements, and they are key to meeting commitments of the Paris Climate Agreement and mitigating the impacts of a changing climate on coastal communities (3). Despite warnings about the ramifications of losing mangroves (4), conversion and degradation still occur (5), especially for smaller mangrove patches.

The global disdain for small mangrove patches is exemplified by the 2017 decision by the Maldivian government to construct a new local airport on the regionally significant mangrove patch (12 ha) on Kulhudhuffushi island (6). This decision was made despite the socioeconomic importance of the mangrove to the local community, the viable alternative solutions that were identified (6), the island's high risk for cyclones and tsunamis (6), and the substantial funding the Maldives received for climate change mitigation and adaptation [e.g., (7)]. Despite assurances that only $30 \%$ of the mangrove would be directly affected by this project, nearly $70 \%$ may have already been destroyed (8).

The loss of relatively small patches of mangrove may seem less concerning than large-scale deforestation. However, these patches are especially important to low-lying island nations vulnerable to climate change and sea level rise (1). Their interconnectedness with adjacent habitats, such as coral reefs, allows them to provide substantial ecosystem services relative to their size (9). The continued loss of mangrove patches further fragments mangrove habitat, which creates barriers to species movement and dispersal (10). The loss also drastically erodes local coastal resilience and pushes key mangrove ecosystems toward collapse.

Given the recent Intergovernmental Panel on Climate Change's projections (11), we simply cannot afford to lose more mangrove forests, irrespective of their size. We call on governments to move away from policy decisions that prioritize large areas and short-term local political gains, and instead adopt a more holistic longterm vision (12), whereby the value of smaller mangrove patches is better appreciated and safeguarded.

David J. Curnick ${ }^{1,2}$, Nathalie Pettorelli, ${ }^{1,2}$, A. Aldrie Amir ${ }^{1,3}$, Thorsten Balke ${ }^{1,4}$,

Edward B. Barbier ${ }^{1,5}$, Stephen Crooks ${ }^{1,6}$, Farid Dahdouh-Guebas ${ }^{1,7,8}$, Clare

Duncan $^{1,2}$, Charlie Endsor ${ }^{1,9}$, Daniel A.
Friess $^{1,10}$, Alfredo Quarto ${ }^{1,11}$, Martin Zimmer $^{1,12}$, Shing Yip Lee ${ }^{1,13}$

${ }^{1}$ Mangrove Specialist Group International Union for the Conservation of Nature (IUCN), Conservation Programmes, Zoological Society of London,

Regents Park, London, NW1 4RY, UK. '2Zoological Society of London, Institute of Zoology, Regents Park, London, NW1 4RY, UK. ${ }^{3}$ Institute for Environment and Development (LESTARI),

Universiti Kebangsaan Malaysia, 43600 Bangi, Selangor, Malaysia. ${ }^{4}$ University of Glasgow, School of Geographical and Earth Sciences, Glasgow, G12 8QQ, UK. ${ }^{5}$ Department of

Economics and School of Global Environmental Sustainability, Colorado State University, Fort Collins, CO 80523, USA. ${ }^{6}$ Silvestrum Climate Associates, San Francisco, CA 94103, USA.

${ }^{7}$ Systems Ecology and Resource Management, Université Libre de Bruxelles, B-1050 Brussels, Belgium. ${ }^{8}$ Department of Ecology and Biodiversity, Vrije Universiteit Brussel, B-1050 Brussels,

Belgium. ${ }^{9}$ Conservation Programmes, Zoological Society of London, Regents Park, London, NW1

4RY, UK. ${ }^{10}$ Department of Geography, National University of Singapore, Singapore 117570 ,

Singapore. ${ }^{11}$ Mangrove Action Project, Seattle, WA 98104, USA. ${ }^{12}$ Leibniz Centre for Tropical Marine Research, ZMT-GmbH, Bremen, Germany. ${ }^{13}$ School of Life Sciences and Earth System Science Programme, The Chinese University of Hong Kong, Shatin, New Territories, Hong Kong SAR, China. ${ }^{*}$ Corresponding author. Email: david.curnick@zsl.org

REFERENCES

1. S. Y. Lee et al., Glob. Ecol. Biogeogr. 23, 726 (2014).

2. B. A. Polidoro et al., PLOS ONE 5, 10.1371/journal.pone.0010095 (2010).

3. P. Taillardat, D. A. Friess, M. Lupascu, Biol. Lett 14, 20180251 (2018).

4. N. C. Duke et al., Science 317, 41 (2007).

5. S. E. Hamilton, D. Casey, Glob. Ecol. Biogeogr. 25, 729 (2016)

6. Z. Hameed, "Environmental Impact Assessment for the airport development project at $\mathrm{Haa}$ Dhaal Kulhudhuffushi” (2017).

7.Green Climate Fund (2018); www.mv.undp.org/content/maldives/en/home/o perations/projects /environment_and_energy/GreenClimateFund html.

8. Transparency Maldives (2018); http://transparency.mv/2018/09/joint-pressstatement-we-call-on-the-authorities-to-ensurethe-protection-of-the-kulhudhuffushimangrove/.

9. E. B. Barbier, in Seascape Ecology, S. J. Pitmann, Ed. (Wiley-Blackwell, NY, 2017), pp. 465-481.

10. L. Triest, Aquat. Bot. 89, 138 (2008)

11. O. Hoegh-Guldberg et al., in "Global warming of $1.5^{\circ} \mathrm{C}$," V. Masson-Delmotte et al., Eds. (2018); www.ipcc.ch/sr15/.

12. A. A. Amir, Science 359, 1342 (2018).

10.1126/science.aaw0809 